\title{
Contraception and Abortion in a Low-Fertility Setting: The Role of Seasonal Migration
}

\section{By Arusyak \\ Sevoyan and \\ Victor Agadjanian}

Arusyak Sevoyan is ARC DECRA Fellow, Australian Population and Migration Centre, University of Adelaide, Australia.

Victor Agadjanian is professor, T. Denny Sanford School of Social and Family Dynamics,

Arizona State University, Tempe, AZ, USA.

\begin{abstract}
CONTEXT: Seasonal labor migration is common among men in many former Soviet republics. Little research has examined contraceptive use and induced abortion among women in such low-fertility, high-migration settings, according to husband's migration status.
\end{abstract}

METHODS: Combined data from 2,280 respondents of two surveys of married women aged 18-45 in rural Armenia-one conducted in 2005 and one in 2007-were used. Logistic regression analyses examined whether a husband's migration status was associated with his wife's current use of the pill or the IUD, or with the probability that she had had a pregnancy that ended in induced abortion. Additional analyses were conducted to determine whether relationships were moderated by household wealth.

RESULTS: Women with a migrant husband were less likely than those with a nonmigrant husband to be currently using the pill or the IUD (odds ratio, 0.6); with increased household wealth, the likelihood of method use increased among women with a nonmigrant husband, but decreased slightly among women with a migrant husband. Overall, the probability that a pregnancy ended in abortion did not differ by migration status; however, the likelihood of abortion increased with wealth among women married to a nonmigrant, but not among those married to a migrant.

CONCLUSIONS: Despite their husband's absence, women married to a migrant may have an unwanted pregnancy rate similar to that of women married to a nonmigrant. Improved access to modern contraceptive methods is likely to be positively associated with contraceptive use among women with a nonmigrant husband, but not among those with a migrant husband.

International Perspectives on Sexual and Reproductive Health, 2013, 39(3):124-132, doi: 10.1363/3912413

Research on the association between migration and fertility regulation remains scarce. The few studies that have looked at permanent migration and contraception found a positive association between the two. ${ }^{1-3}$ Spousal separation due to temporary migration of one partner, however, has been found to be negatively associated with contraceptive use. According to a study among women in Malaysia, migrants were less likely than nonmigrants to use contraceptives; ${ }^{4}$ the researchers speculate that their finding may reflect migrant women's greater likelihood of being separated from their spouse before and after migration. Among Guatemalan women, those separated from their husband because of migration or other reasons were less likely than those not separated to use any contraceptive method. ${ }^{2}$ Evidence from South Africa also supports the negative association between men's temporary migration and women's contraceptive use, not only because of lower coital frequency and, therefore, lower risk of pregnancy, but also because men's absence may increase the demand for children among women in unstable relationships, to ensure their future support. ${ }^{5}$ In another South African study, lower use of contraceptives among partners of migrants was attributed to women's being less likely to communicate with their partner about contraception the less frequently they saw him. ${ }^{6}$
Spousal communication can be an important determinant of contraceptive use in settings where women socially and economically depend on their husbands. ${ }^{7-9}$

Along with contraception, induced abortion is a major proximate determinant of fertility. The determinants of induced abortion vary across countries according to prevailing individual and institutional attitudes toward the practice. For example, in China, abortion rates were strongly affected by official family planning policies and regulations, but not by household socioeconomic status. ${ }^{10}$ In Bangladesh, induced abortion was linked to high parity, short pregnancy interval, higher maternal education and high rate of contraceptive failure, ${ }^{11}$ whereas in Nigeria, abortion was associated with woman's older age, higher education and greater use of family planning methods. ${ }^{12}$

To our knowledge, no study has examined the relationship between seasonal migration and abortion. This relationship is of particular interest in settings where both migration and abortion are widespread. The former Soviet Union has seen massive permanent and seasonal migration, primarily flowing from the former Soviet republics in the Caucasus and Central Asia toward the Russian Federation. ${ }^{13}$ In addition, abortion has been a primary method of fertility control in the region for decades. The Soviet 
Union is believed to be the only country to achieve fertility transition through widespread use of induced abortion. ${ }^{14,15}$ Since the 1950s, as much as $80 \%$ of the region's reproductive-age population were using induced abortion as a method of fertility control. ${ }^{14}$ Although abortion rates appear to have declined in the post-Soviet era, abortion remains common throughout the region. ${ }^{16}$

Despite the massive migration in the former Soviet republics, no study has examined the relationships between migration, contraception and abortion there. Our study looks at the association of men's seasonal migration with the use of medium- and long-term contraceptives and the practice of abortion among their female partners in rural Armenia, a nation that gained independence after the dissolution of the Soviet Union. We focus on medium- and long-term modern contraceptives, such as the IUD and the pill, because they require continuous use for maximum effectiveness, even when spouses are separated. Short-term methods, such as the male condom, can easily be started and discontinued; therefore, use of short-term methods is difficult to relate to the spousal separation.

A previous study in Armenia found that yearly pregnancy rates, fertility preferences and lifetime fertility did not differ between women with a migrant husband and those with a nonmigrant husband in analyses controlling for individual-, household- and community-level characteristics. ${ }^{17}$ Thus, there is no evidence that the disruptive effect of seasonal migration on fertility found in high-fertility areas is also present in this low-fertility setting.

\section{Setting}

- Migration in Armenia. Labor migration is common in Armenia, a nation of some three million people with an estimated gross national per capita income of $\$ 3,720 .{ }^{18}$ Two main patterns of international migration occur: permanent emigration, mainly from Yerevan-Armenia's capital and by far its largest city-to Europe and the United States, and seasonal labor migration from rural areas to Russia and, to a lesser extent, other countries of the former Soviet Union. ${ }^{19}$ There are no official data on the volume of seasonal labor migration from Armenia. According to some estimates, the share of Armenian households involved in labor migration was 8-9\% between 2002 and $2007 .{ }^{20}$ The vast majority of seasonal migrants (94\%) were men aged 21-55, three-fourths of whom were married.

According to a study of labor migration, more than $75 \%$ of migrants leave home by the end of spring and return between October and December, ${ }^{20}$ the average duration of labor migration is about eight months. Another study found similar results: a well-developed seasonal pattern of migration mostly to Russia, in which people leave between January and August to work in construction and agriculture, and return between September and December. ${ }^{13}$

Seasonal migration in Armenia can lead to permanent migration, especially as the rural economy stagnates. According to one study, seasonal migration was negatively associated with economic attachment to the home com- munity. ${ }^{21}$ Moreover, women with a migrant husband were more likely than women with a nonmigrant husband to wish to move abroad, regardless of economic attachment, social engagement or any other individual-, household- or community-level indicator; this difference increased with the cumulative duration of husband's migration.

- Contraception and abortion in Armenia. Armenia is among the many countries in Eastern Europe and Asia with very low levels of fertility. ${ }^{22}$ Armenia's total fertility rate declined from 2.6 children per woman in 1990 to 1.2 in 1999, establishing it as one of the lowest levels in the world; it rose slightly (to 1.4) in the early 2000s. ${ }^{23}$

Low fertility in Armenia has not been associated with widespread contraceptive use. ${ }^{22}$ Reliable data on contraception in Armenia are limited; however, according to the 2005 Armenia Demographic and Health Survey (ADHS), * $47 \%$ of married women (almost none of whom wanted to have more children) were not doing anything to prevent pregnancy, and half of them did not intend to use any method in the future. ${ }^{24}$ One-third of married Armenian women currently relied on traditional methods, of which withdrawal was the most common. Only 39\% of married women had ever used a modern method, and 20\% were currently using one. The most widely used modern method among married women was the IUD ( $9 \%$ ), followed by the male condom ( $8 \%$ ); only $1 \%$ used the pill.

Women more commonly practiced contraception to limit fertility than to delay initiation of childbearing: Fewer than $2 \%$ of married women initiated contraceptive use before their first birth, while $18 \%$ did so after their first birth and $21 \%$ after their second birth. ${ }^{24}$

Armenia has high levels of induced abortion as well as low levels of modern contraceptive use. According to the 2005 ADHS, 37\% of all women had had at least one induced abortion, ${ }^{24}$ women's mean number of abortions was 2.6. Rural areas had much higher abortion rates than urban areas (64 vs. 48 per 1,000). Abortion was used mainly to limit fertility and less often to space births: Fewer than $1 \%$ of abortions occurred before a woman's first birth, 21\% after her first birth, and 64\% after her second birth. More than half (55\%) of women who had had an abortion reported using a traditional method at the time they conceived their last pregnancy that ended in an abortion, and only 9\% reported using a modern method at that time. ${ }^{25}$ The reported failure rates of the male condom and the IUD were $5 \%$ and $1 \%$, respectively. ${ }^{25}$ Because the failure rate of modern contraceptives is low, induced abortion for the purpose of this analysis is considered as an alternative to modern contraceptives.

\section{Conceptual Framework}

The importance of understanding the determinants of fertility regulation has been stressed in the economic theory of fertility. ${ }^{26,27}$ Fertility regulation is shaped by both the

*Although data from the 2010 ADHS are now available, we use the 2005 ADHS because it was closer to our data collection time. 


\begin{tabular}{|c|c|}
\hline Characteristic & $\begin{array}{l}\% \text { or mean } \\
(\mathrm{N}=2,280)\end{array}$ \\
\hline \multicolumn{2}{|l|}{ Migration status of husband } \\
\hline Nonmigrant & 59.3 \\
\hline Migrant & 40.7 \\
\hline Mean age & 32.7 \\
\hline Mean age difference from husband & 5.0 \\
\hline Mean age at marriage & 19.4 \\
\hline \multicolumn{2}{|l|}{ Education } \\
\hline$\leq$ secondary & 60.3 \\
\hline zvocational & 39.7 \\
\hline \multicolumn{2}{|l|}{ Husband's education } \\
\hline$\leq$ secondary & 64.3 \\
\hline zvocational & 35.7 \\
\hline \multicolumn{2}{|l|}{ Employed outside the home } \\
\hline No & 86.7 \\
\hline Yes & 13.3 \\
\hline \multicolumn{2}{|l|}{ Sex composition of childrent } \\
\hline 1 child:boy & 6.4 \\
\hline 1 child:girl & 4.4 \\
\hline$\geq 2$ children:boys only & 16.4 \\
\hline$\geq 2$ children: girls only & 8.4 \\
\hline$\geq 2$ children:boys and girls & 64.4 \\
\hline \multicolumn{2}{|l|}{ Wants more children } \\
\hline No & 75.3 \\
\hline Yes & 24.7 \\
\hline \multicolumn{2}{|l|}{ Survey location/year } \\
\hline Gegharkunik/2007 & 54.4 \\
\hline Ararat/2005 & 22.8 \\
\hline Tavush/2005 & 22.8 \\
\hline Current IUD use & 8.2 \\
\hline Current pill use & 1.5 \\
\hline \multicolumn{2}{|l|}{ Ever had an abortion } \\
\hline No & 48.9 \\
\hline Yes & 51.1 \\
\hline Mean no. of abortions‡ & 2.7 \\
\hline
\end{tabular}

†Among women with at least one child. ¥Among women who had had at least one abortion.

motivation to limit the number of children and the costs fertility regulation imposes on the household. ${ }^{26}$ The latter involves three types of cost: economic (e.g., the time and money required to obtain contraceptive methods), social (the perceived risk of violating social norms) and psychic (personal fears of health effects). ${ }^{27}$

On the basis of this framework, we first examine whether seasonal migration is associated with current use of medium- and long-term modern contraceptive methods. Given previous research on migration and contraceptive use, ${ }^{4-6}$ we assume that women married to a migrant would have much lower motivation to practice contraception than women married to a nonmigrant, because they may consider themselves at a lower risk of pregnancy, at least while their husband is away. At the same time, such women may also have lower motivation to use contraceptives when their husband is home, because the couple might want to use their time together to achieve their preferred number of children. It is also possible that spousal communication about contraception in a culturally conservative, patriarchal setting is even less common for women with a migrant husband than for those with a nonmigrant huband. ${ }^{6}$ Therefore, we hypothesize that the husband's seasonal migration will be negatively associated with contraceptive use.

In addition, we explore whether any relationship between seasonal migration and contraceptive use might be moderated by economic well-being. On the basis of the economic framework of fertility regulation, better access to contraceptives and family planning services afforded by increased affluence would be expected to be positively associated with contraceptive use among women. However, among women with a migrant husband, use of mediumand long-term contraceptives is likely to be more strongly influenced by a lack of need for pregnancy prevention when their husband is absent than by access to contraceptives. Therefore, we propose that increased affluence will result in a higher contraceptive rate among nonmigrants' wives, but not among migrants' wives.

Next, we examine whether seasonal migration is associated with induced abortion. In the absence of contraceptives, or assuming equal use of them by migrants' and nonmigrants' wives, the rate of unwanted pregnancy-and therefore, of abortion-would likely be lower among migrants' wives than among nonmigrants' wives, because of less frequent intercourse. However, assuming that mediumand long-term contraceptive use is lower among migrants' wives than among nonmigrants' wives, the reduction of the likelihood of pregnancy among migrants' wives when their husband is away would be comparable to that from use of long-term contraceptives among nonmigrants' wives, resulting in approximately equal chances of unwanted pregnancy. We, therefore, hypothesize that the two groups of women will have similar abortion rates. We should note that in the cultural context of rural Armenia, where sexual partnerships outside of marriage are extremely uncommon among married women, ${ }^{24}$ extramarital pregnancies are rare and unlikely to have any appreciable influence on abortion rates among women with a migrant husband or those with a nonmigrant husband.

As with contraception, we also explore whether any relationship between seasonal migration and abortion might be moderated by economic well-being. Given that abortion has continued to be a primary method of fertility regulation in the post-Soviet era, the determinants of abortion are the same as those of contraception: motivation and costs. Thus, increased affluence is likely to increase access to abortion services. On the other hand, the impact of increased access to abortion services on use of those services by migrant couples is likely to be canceled out by their higher fertility preferences due to greater optimism about the future, ${ }^{6}$ or because of low exposure to pregnancy risk. Therefore, we expect that increased affluence-and therefore, better access to abortion services-will be associated with increased abortion rates only among women married to a nonmigrant. 


\section{DATA AND METHODS}

\section{Data}

For our study, we used data from two surveys of women in marital union (registered or unregistered) in rural Armenia. Although having sexual intercourse before marriage is not uncommon among men, women-especially in rural areas-usually experience sexual debut at marriage. According to the 2005 ADHS, women's age at marriage and age at first intercourse correspond almost exactly, ${ }^{24}$ which indicates that the fraction of unmarried women at risk of pregnancy is very small.

The first survey was the Migration, Social Capital, and Reproductive Behavior and Outcomes survey, conducted in 2005 in 52 villages of two marzes (provinces)-Tavush and Ararat. Ararat, located close to the capital city of Yerevan, is one of Armenia's most fertile regions and is relatively prosperous compared with Tavush, which borders Georgia and Azerbaijan and is among the country's poorest regions. In each village, 20 households with married women aged 18-45 were selected through a random walk algorithm, for a sample of 1,040 women. The second survey-the Labor Migration and STD/HIV Risks surveywas carried out in 2007 in rural areas of Gegharkunik province, which is also one of Armenia's poorest regions and has very high rates of seasonal labor migration. A threestage sampling procedure was used to select 1,240 married women aged $18-45$. In total, the combined sample consisted of 2,280 women.

The sampling procedure in both surveys was designed to ensure a balanced representation of women from seasonal migrant and nonmigrant households. For each, we defined "seasonal migrant" as a husband who had left for seasonal work outside of the country for at least three months between the beginning of the year and the time of survey. Both surveys were conducted during the migration season, when most of the men were away. Some villages did not have enough eligible or available women with a migrant husband; in such cases, we interviewed additional randomly selected women married to nonmigrants to ensure that the sample size in each village was the same. As a result, the proportion of nonmigrant households exceeded the proportion of migrant households in both surveys (63\% vs. $37 \%$ in 2005 , and $56 \%$ vs. $44 \%$ in 2007 ). It should be stressed that the sampling procedures were not meant to produce a province- or village-level representative sample of women married to migrants and nonmigrants, but rather to ensure sound comparisons between the two categories of rural women.

Both survey instruments contained identical questions on household structure and individual social and demographic characteristics; marriage and husband's characteristics, including husband's migration history; health and reproductive history, including the timing and outcome of all pregnancies; social capital and community; household economic characteristics and living conditions; and gender attitudes. Husband's migration history was collected for the period of 2000-2005 for the 2005 survey, and for
TABLE 2. Odds ratios from random-intercept logistic regression models assessing women's likelihood of current use of the pill or IUD, by selected characteristics

Characteristic

Model 1 Model 2 Model 3

Migration status of husband

Nonmigrant (ref)

Migrant

Age

Age squared

Age difference from husband

Age at marriage

Education

$\leq$ secondary (ref)

$\geq$ vocational

Husband's education

$\leq$ secondary (ref)

$\geq$ vocational

Employed outside the home No (ref)

Yes

Sex composition of children

1 child:boy

1 child:girl

$\geq 2$ children:boys only

$\geq 2$ children: girls only

$\geq 2$ children: boys and girls (ref)

$\begin{array}{lll}1.00 & 1.00 \quad 1.00\end{array}$

$0.53^{* *} \quad 0.55^{* *} \quad 0.56^{* *}$

Wants more children

No (ref)

Yes

na $1.29^{*} \quad 1.28^{*}$

na $1.00^{*} \quad 1.00^{*}$

$1.01 \quad 1.01$

$\begin{array}{ll}1.01 & 1.01 \\ 1.00 & 1.00\end{array}$

na

$\begin{array}{lll}1.00 & 1.00\end{array}$

na $\quad 0.95 \quad 0.95$

Household asset

component-secondary

Household asset

component-primary

Migrant*secondary assets

Migrant*primary assets

No. of households in village

na $\quad 1.00 \quad 1.00$

na $1.34 \dagger \quad 1.34 \dagger$

Survey location/year

Gegharkunik/2007 (ref)

Ararat/2005

Tavush/2005

-2 res log pseudo-likelihood

na $\quad 1.00 \quad 1.00$

na $\quad 0.87 \quad 0.85$

${ }^{*} \mathrm{p}<.05 .{ }^{* *} \mathrm{p}<.01 .+\mathrm{p}<.10$. Notes: ref=reference group. $\mathrm{na}=$ not applicable. Analytic sample contained 2,078 women.

the period of 2001-2007 for the 2007 survey, or since marriage if it happened after 2000-2001.

\section{Migration and Contraception}

We conducted binomial logistic regression to examine the relationship between migration status and woman's current use of medium- and long-term modern contraceptive methods at the time of the survey. We excluded from this analysis women who were pregnant at the time of the survey. In addition, because the rate of contraceptive use in Armenia is extremely low among nonparous women, ${ }^{24}$ we excluded women who had not had at least one prior birth, which resulted in a final analytical sample of 2,078 women.

Our outcome variable was women's current use of either oral contraceptive pills or the IUD (coded 1 for yes and 0 for no); we focused on the pill and the IUD because respondents did not report use of other medium- and 


\section{FIGURE 1. Predicted probablilty of women's current use of the pill or IUD, by husband's migration status, according to selected values of household asset component scores}
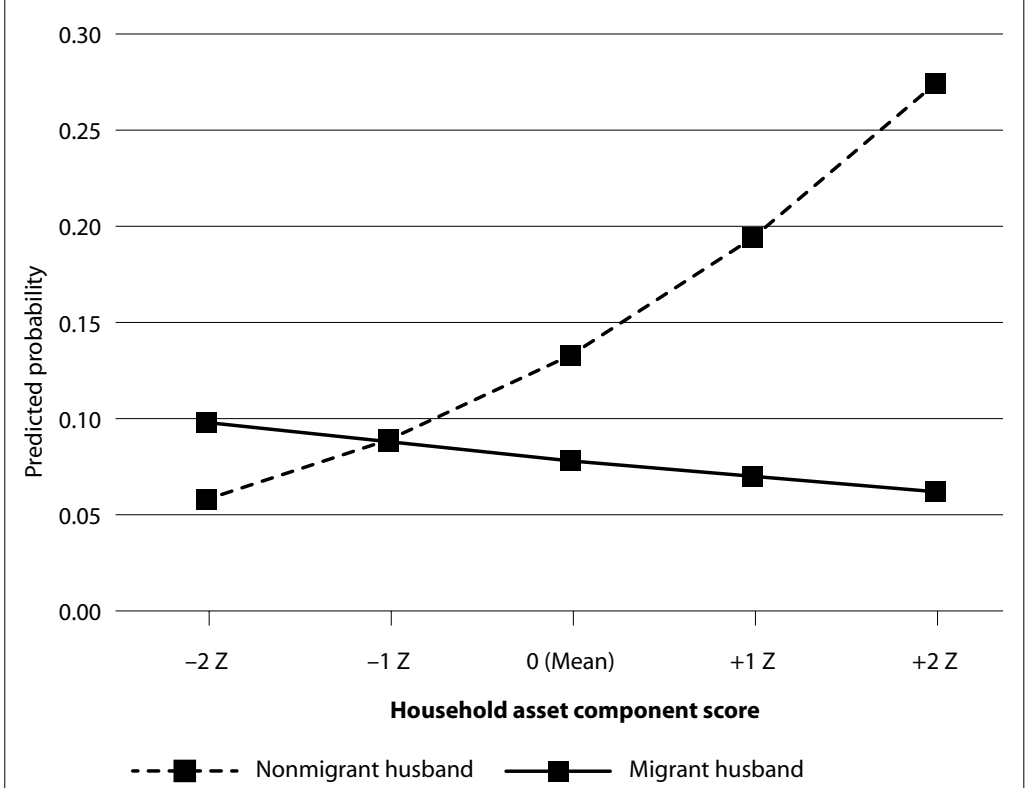

Notes: $\mathrm{Z}=$ standard deviation. Household asset score represents the values of both primary and secondary asset components. or two or more children (boys and girls). The mixed gender category was used as the reference category. Also, we used principal component analysis* to create measures of household economic well-being from responses to six survey items about household ownership of the following items in working condition: color TV, stereo system, video or DVD player, refrigerator, gas or electric stove and automobile. Ownership of a stereo system, a video or DVD player and a car loaded on the first component, labeled as "secondary necessity assets component," while having a TV, refrigerator and a stove loaded on the second component, labeled as "primary necessity assets component." Moreover, we controlled for village population sizemeasured as the number of households in the village in hundreds-which is a proxy for the level of socioeconomic development, as larger villages usually have more developed economies and infrastructures than smaller ones. Finally, we included a measure for survey location, which controlled for differences across provinces and in the design between the two surveys. To account for villagelevel clustering and to protect against deflated standard errors that might bias the hypothesis testing, the randomintercept approach was used, which allowed the intercept to vary randomly by village. ${ }^{29}$ We fit the model using the GLIMMIX procedure for binary distribution in SAS.

\section{Migration and Abortion}

We used random-intercept logistic regression to examine the relationship between migration status and the probability of a pregnancy ending in induced abortion; the unit of analysis was a pregnancy. Because the abortion rate in Armenia is less than 1\% among women with no live births, ${ }^{24}$ we excluded from analyses of abortion pregnancies that occurred to women before they had had their first live birth. In addition, because husband's migration history was available only since 2000-2001, the analysis was further limited to pregnancies that occurred during that period, or since marriage if the union started after 2000-2001. Although this is a limitation of the study, one should keep in mind that more recent events tend to be more accurately reported. Besides, a focus on a relatively recent past allowed us to include some controls measured at the time of survey. Our final analytic sample consisted of 2,055 pregnancies.

Our dependent variable for this analysis was whether a pregnancy ended in an induced abortion (coded 1 for yes and 0 for no). The main predictor was husband's seasonal migration status in the year of the pregnancy (coded 1 for migrant and 0 for nonmigrant).

Control variables consisted of respondent's age in the year of the pregnancy, age discrepancy with husband, age at marriage, education, employment outside of the home in the year of the pregnancy and number of children born before the index pregnancy by sex composition; measures were coded the same as in the analysis of contraceptive use. The model also included measures for husband's education and household economic well-being. Although 
household affluence was measured at the time of the survey, it is still an adequate proxy for household well-being in this model, considering the relatively short observation span, as well as the fact that assets are usually accrued over a period of time and represent the cumulative wealth of the household. In addition, we included controls for the number of households in the village and the location and year of the survey. Again, we used the GLIMMIX procedure for binary outcomes to fit this model; it allowed the intercept of the outcome variable to vary randomly not only by village, but also by woman, because pregnancies are also clustered within women.

\section{RESULTS}

Overall, $41 \%$ of women surveyed had a migrant husband (Table 1, page 126). The mean age of the sample was 33 years; on average, women were five years younger than their husband. Only 13\% of women reported working outside the home. Most women had two or more children-64\% percent both girls and boys, $16 \%$ only boys and $8 \%$ only girls; the remainder had only one child (6\% a boy and $4 \%$ a girl). Three-fourths reported not wanting to have any more children. Eight percent of women were currently using the IUD, and 2\% were currently using the pill. Half had ever had an abortion; among those, the mean number of abortions was 2.7 .

\section{Migration and Contraceptive Use}

In an initial analysis of husband's seasonal migration status and current contraceptive use without control measures (Table 2, page 127), women with a migrant husband had $47 \%$ lower odds than those with a nonmigrant husband of using the pill or IUD (odds ratio, 0.5). The addition of controls in the second model only slightly attenuated the strong negative association between migration and contraceptive use.

The third model included interaction terms for husband's migration status and household assets, but the result did not change substantially: Women with a migrant husband had $44 \%$ lower odds than other women of using the pill or IUD (odds ratio, 0.6). The conditional effect of the household assets components-representing the effect of affluence on contraceptive use for women in nonmigrant households-was positive. A one-unit increase in the secondary-needs assets component was associated with a 29\% increase in the odds of contraceptive use among women with a nonmigrant husband; a one-unit increase in the primary-needs assets component was associated with a $22 \%$ increase in the outcome. For women with a migrant husband, however, the effect of household economic wellbeing-represented by the combined effects of household asset components and the interaction terms-tells a different story.

For easier understanding and interpretation of the relationship between migration, household economic well-being and contraceptive use, we present the predicted probability of current contraceptive use by husband's migration
TABLE 3. Odds ratios from random-intercept logistic regression models assessing the likelihood that a pregnancy ended in induced abortion, by selected characteristics

Characteristic

Model 1 Model 2 Model 3

Migration status of husband

Nonmigrant (ref)

Migrant

Age

Age difference from husband

Age at marriage

$\begin{array}{lll}1.00 & 1.00 & 1.00 \\ 1.24 \dagger & 0.95 & 0.98\end{array}$

Education

$\leq$ secondary (ref)

$\geq$ vocational

Husband's education

$\leq$ secondary (ref)

$\geq$ vocational

Employed outside the home

No (ref)

Yes

Sex composition of children

1 child:boy

1 child:girl

$\geq 2$ children: boys only

$\geq 2$ children:girls only

$\geq 2$ children: boys and girls (ref)

na $1.08^{* *} \quad 1.08^{* *}$

na $0.98 \quad 0.98$

na $\quad 0.93 \dagger \quad 0.93 \dagger$

Household asset

component-secondary

Household asset

component-primary

Migrant*secondary assets

Migrant*primary assets

No. of households in village

$0.93+$

na $\quad 1.00 \quad 1.00$

$\begin{array}{lll}\text { na } & 0.90 & 0.88\end{array}$

Survey location/year

Gegharkunik/2007 (ref)

Ararat/2005

Tavush/2005

na $\quad 1.00 \quad 1.00$

na $\quad 0.98 \quad 0.97$

-2 res log pseudo-likelihood

$1.00 \quad 1.00$

na $\quad 1.59 \quad 1.58$

${ }^{*} \mathrm{p}<.05$. ${ }^{* *} \mathrm{p}<.01 .+\mathrm{p}<.10$. Notes: ref=reference group. na=not applicable. Only pregnancies in the five years before the survey or since marriage (if married less than five years before survey) are considered. Analytic sample contained 2,055 pregrancies.

status for different values of the household asset components (Figure 1).* At the lowest end of the household asset scale (i.e., two standard deviations below the mean), contraceptive use was more likely among women with a migrant husband than among those with a nonmigrant husband (predicted probabilities, 0.10 and 0.06, respectively). As wealth increased, the probability of contraceptive use gradually increased among woman with a nonmigrant husband, but declined slightly among women with a migrant husband. So, at one standard deviation below the mean of household assets, contraceptive use was the same for women with migrant and nonmigrant husbands (0.09 each). At the highest end of the household asset scale (i.e., two standard deviations above the mean), contraceptive use was substantially more likely among women with a

*For simplicity and to understand the overall effect of household affluence on contraceptive use, each value on the $\mathrm{x}$-axis represents the values of both household assets components. 
FIGURE 2. Predicted probability of a pregnancy ending in abortion, by husband's migration status, according to selected values of household asset component scores

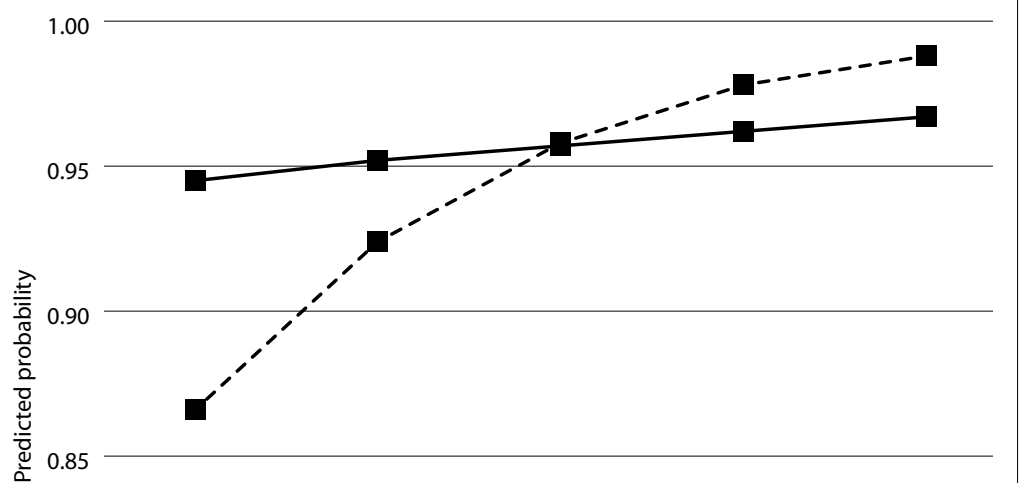

0.80

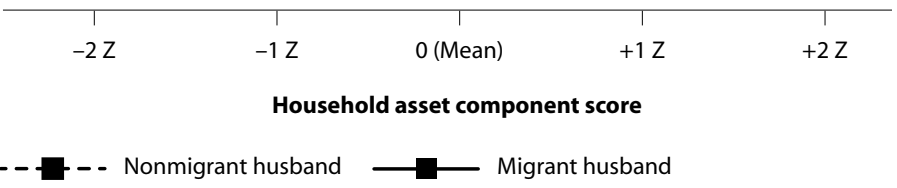

Notes: $\mathrm{Z}=$ standard deviation. Household asset score represents the values of both primary and secondary asset components. see that the likelihood of abortion was about the same for women with a migrant husband regardless of wealth (predicted probabilities, 0.95-0.97). Among women with a nonmigrant husband, however, the predicted probability of abortion rose with increased wealth, from 0.87 at the lowest asset level to 0.99 at the highest. At the lowest end of household economic well-being, the probability of abortion was higher among women married to a migrant than among those married to a nonmigrant. At the highest end, however, the difference between the groups was negligible.

\section{DISCUSSION}

Research on migration and reproduction has focused mostly on permanent migration or on high-fertility settings; research on seasonal migration and reproductive behavior and outcomes in the former Soviet Union-where vast societal and demographic changes have occurred in the past two decades-is particularly limited. Our study contributes to the literature on temporary migration and fertility regulation from a former Soviet country with belowreplacement fertility, low contraceptive use, widespread abortion and high levels of male seasonal migration.

Our results suggest a negative association between temporary migration and contraceptive use in the lowfertility context of rural Armenia. As we expected, the use of medium- and long-term modern contraceptives was lower among women with a migrant husband than among those married to a nonmigrant in analyses controlling for other factors; women's reduced perceived need for continuous protection from pregnancy during their husband's absence is most likely the explanation. However, we found that the association between seasonal migration and contraceptive use was moderated by the level of household economic well-being. In nonmigrant households, greater affluence was associated with higher levels of contraceptive use. This is most likely explained by the improved access to family planning services and greater availability of modern contraceptives afforded by wealth. In comparison, no such wealth-related increase in contraceptive use was observed among migrant households. In fact, contraceptive use declined slightly as wealth increased.

We can propose several tentative explanations for this difference. Motivation to use contraceptives may be very low among women married to a migrant, so that increased access to modern methods does not affect their contraceptive use. Moreover, wealth in migrant households may be a proxy for longer history and duration of husband's absence, ${ }^{21}$ which in turn may lead to women's lower perceived pregnancy risk and correspondingly lower need for contraception. Longer migration has also been found to decrease spousal communication about contraception and sexual health. ${ }^{6}$ Although the national data show that the duration of the migration season is more or less uniform in rural Armenia, ${ }^{20}$ the possibility of a cumulative effect of the duration of husband's absence on contraceptive use appears plausible. Unfortunately, our data did not allow us to directly measure duration of husbands' absence. 
Alternatively, or additionally, the perception of lower pregnancy risk among women married to a migrant may be related to higher secondary infertility or subfertility due to STI: The likelihood of STI is positively associated with household affluence among wives of migrants. ${ }^{30}$ Increased wealth could also mean women's increased ability to afford an abortion, the risk of which-given husbands' short stays between seasonal migrations-women may perceive as lower than the health risks from medium- or long-term use of "unnatural" contraceptive methods. Finally, wealth could increase the ability to afford the costs of having an additional child, which might be a more acceptable scenario for migrants-especially those contemplating permanent migration-than for nonmigrants.

Our findings on induced abortion suggest that although women's overall probability of terminating a pregnancy does not differ by husband's migrant status, the association between household economic well-being and pregnancy termination does. Among women with a migrant husband, the likelihood of abortion did not change across the affluence spectrum; however, among women with a nonmigrant husband, the probability of abortion increased with increased wealth. We reason that with wealth, abortion services become more affordable for both women married to a migrant and those married to a nonmigrant. However, affluence may promise a better future for migrant families, who are more likely than nonmigrant families to associate it with the prospect of moving to a more prosperous country. Couples who are more optimistic about their future may feel less inclined to terminate a pregnancy. Thus, for more affluent migrant households, their greater optimism about the future may offset their increased ability to pay for abortion.

The possibility of reverse causation between economic well-being and abortion rates must also be acknowledged, as household wealth was measured at the time of the survey, rather than at the time of pregnancy. It is possible that abortion-by limiting household size-increases household savings, which in turn are more likely to be invested in household assets by nonmigrant families than by migrant families, who are usually less economically attached to their communities. ${ }^{21}$ It is also possible that the timing of the survey may have had some influence on the results. The data were collected at the peak of migration season when the perceived risks of conception might be lowest and women who typically use a contraceptive only during their husband's short visits home may not have been using one. This might be a possible scenario for women who rely on the pill, although pill use among women in our sample was low. The IUD was by far the more popular contraceptive method, but the considerable costs in terms of time and money would likely prohibit women in this rural setting from inserting and removing the method according to their husband's migration. Thus, we do not think that the survey timing biased our results.

The study's limitations notwithstanding, its findings provide support for the negative associations between mi- gration and contraceptive use found in the literature from high-fertility settings. They also indicate that women with a migrant husband and those with a nonmigrant husband are equally likely to abort a pregnancy, which in the context of very low contraceptive use means equally high abortion rates for both groups. Hence, women married to a migrant-despite their low risk of conception when their husbands are away most of the year-may have an unwanted pregnancy rate similar to that of women married to a nonmigrant. And while improved access to modern contraceptive methods is likely to increase their use among nonmigrants' wives, it is unlikely to have a comparable effect on the use of these methods among migrants' wives, because of their lower motivation to practice contraception.

There is a great need in Armenia for programs promoting the benefits of modern contraception over abortion for fertility control, particularly among families of seasonal migrants. Without such efforts, increased availability of modern methods may not lead to an increase in their use.

\section{REFERENCES}

1. Moreno L, Residential mobility and contraceptive use in northeastern Brazil, DHS Working Papers, Calverton, MD, USA: Macro International, 1994, No. 9.

2. Lindstrom DP and Muñoz-Franco E, Migration and the diffusion of modern contraceptive knowledge and use in rural Guatemala, Studies in Family Planning, 2005, 36(4):277-288.

3. Lindstrom DP and Hernández $\mathrm{CH}$, Internal migration and contraceptive knowledge and use in Guatemala, International Family Planning Perspectives, 2006, 32(3):146-153.

4. DaVanzo J and Goldstein S, Migration and Fertility: Some Illustrative Tabulations Based on the Malaysian Family Life Survey, Santa Monica, CA, USA: RAND, 1979.

5. Kaufman CE, Contraceptive use in South Africa under apartheid, Demography, 1998, 35(4):421-434.

6. Hughes GD, Hoyo C and Puoane TR, Fear of sexually transmitted infections among women with male migrant partners-relationship to oscillatory migration pattern and risk-avoidance behaviour, South African Medical Journal, 2006, 96(5):434-438.

7. Link CF, Spousal communication and contraceptive use in rural Nepal: an event history analysis, Studies in Family Planning, 2011, 42(2):83-92.

8. Sharan M and Thomas W, Spousal communication and family planning adoption: effects of a radio drama serial in Nepal, International Family Planning Perspectives, 2002, 28(1):16-25.

9. Lasee A and Becker S, Husband-wife communication about family planning and contraceptive use in Kenya, International Family Planning Perspectives, 1997, 23(1):15-20 \& 33.

10. Ping $T$ and Smith HL, Determinants of induced abortion and their policy implications in four counties in north China, Studies in Family Planning, 1995, 26(5):278-286.

11. Ahmed MK, Rahman M and van Ginneken J, Induced abortions in Matlab, Bangladesh: trends and determinants, International Family Planning Perspectives, 1998, 24(3):128-132.

12. Okonofua FE et al., Assessing the prevalence and determinants of unwanted pregnancy and induced abortion in Nigeria, Studies in Family Planning, 1999, 30(1):67-77.

13. Heleniak T, An overview of migration in the Post-Soviet space, in: Buckley CJ, Ruble B and Hofman E, eds., Migration, Homeland, and Belonging in Eurasia, Baltimore, MD, USA: Johns Hopkins University Press, 2008, pp. 29-69.

14. Remennick LI, Epidemiology and determinants of induced abortion in the U.S.S.R, Social Science \& Medicine, 1991, 33(7):841-848. 
15. Popov AA, Family planning and induced abortion in the USSR: basic health and demographic characteristics, Studies in Family Planning, 1991, 22(6):368-377.

16. Agadjanian V, Is "abortion culture" fading in the former Soviet Union? Views about abortion and contraception in Kazakhstan, Studies in Family Planning, 2002, 33(3):237-248.

17. Sevoyan A, The Consequences of Male Seasonal Migration for Women Left Behind: The Case of Rural Armenia, doctoral dissertation, Phoenix, AZ: Arizona State University, 2011.

18. The World Bank, Countries and Economies: Armenia, Washington, DC: The World Bank, <http://data.worldbank.org/country/armenia>, accessed Aug. 13, 2013

19. Gevorkyan AV, Mashuryan $\mathrm{K}$ and Gevorkyan A, Economics of Labor Migration from Armenia: A Conceptual Study, Washington, DC: Armenian International Policy Research Group, 2006.

20. Minasyan A et al., Labor Migration from Armenia in 2005-2007: A Survey, Yerevan, Armenia: Asoghik, 2007.

21. Agadjanian V and Sevoyan A, Embedding or uprooting? The effects of international labor migration on rural households in Armenia, International Migration, 2013, doi: 10.1111/imig.12058, accessed Aug. 13, 2013.

22. Billingsley S, Fertility behavior in Armenia and Moldova: the decline during the Post-Soviet transition and current preferences, DHS Working Papers, Calverton, MD, USA: Macro International, 2008, No. 45.

23. United Nations Children's Fund (UNICEF), TransMONEE Database, 2008, 2008, <http://www.unicef-irc.org/databases/ transmonee/\#TransMONEE>, Nov. 15, 2009.

24. National Statistical Service of the Republic of Armenia, Ministry of Health, Armenia and ORC Macro, Armenia Demographic and Health Survey 2005, Calverton, MD, USA: National Statistical Service, Ministry of Health, Armenia and ORC Macro, 2006.

25. Westoff CF et al., Contraception-abortion connections in Armenia, DHS Analytical Studies, Calverton, MD, USA: ORC Macro, 2002, No. 6.

26. Easterlin RA, An economic framework for fertility analysis, Studies in Family Planning, 1975, 6(3):54-63.

27. Robinson WC, The economic theory of fertility over three decades, Population Studies, 1997, 51(1):63-74.

28. Duthé $G$ et al., High sex ratios at birth in the Caucasus: modern technology to satisfy old desires, Population and Development Review, 2012, 38(3):487-501

29. Schabenberger O, Introducing the GLIMMIX Procedure for Generalized Linear Mixed Models, Cary, NC, USA: SAS Institute, 2009. No. 196-30.

30. Sevoyan A and Agadjanian V, Male migration, women left behind and sexually transmitted diseases in Armenia, International Migration Review, 2010, 44(2):354-375.

\section{RESUMEN}

Contexto: La migración estacional de mano de obra es común entre los hombres de muchas repúblicas de la antigua Unión Soviética. Se han realizado pocas investigaciones para examinar el uso de anticonceptivos y el aborto inducido en las mujeres en tales entornos de baja fecundidad y alta migración, según el estatus de migrante del esposo.

Métodos: Se usaron datos combinados de 2.280 personas que respondieron a dos encuestas de mujeres casadas en edades de 18-45 en Armenia rural-una realizada en 2005 y otra en 2007.Usando análisis de regresión logística, se examinó si el estatus migratorio del esposo estaba asociado con el uso actual de la píldora o el DIU por parte de la esposa, o con la probabilidad de que ella hubiera tenido un embarazo que terminara en aborto inducido. Se realizaron análisis adicionales para determinar si las relaciones estaban siendo moderadas por la situación económica del hogar.

Resultados: Las mujeres con un esposo migrante tuvieron menos probabilidad que aquellas con un esposo no migrante de estar usando en la actualidad la píldora o el DIU (cociente de probabilidades 0,6); con una mejor situación económica en el hogar, la probabilidad de uso de un método aumentó entre las mujeres con un esposo no migrante, y disminuyó ligeramente entre las mujeres con un esposo migrante. En general, la probabilidad de que un embarazo terminara en aborto no difirió en función del estatus migratorio; sin embargo, la probabilidad de aborto aumentó entre las mujeres casadas con un no migrante que están en una mejor situación económica, pero no así entre las casadas con un migrante.

Conclusiones: A pesar de la ausencia del esposo, es posible que las mujeres casadas con un migrante tengan una tasa de embarazo no deseado similar a la de las mujeres casadas con un no migrante. Es probable que un mejor acceso a los métodos de anticoncepción modernos esté asociado positivamente con el uso de anticonceptivos en mujeres con un esposo no migrante, pero no en aquellas con un esposo migrante.

\section{RÉSUMÉ}

Contexte: La migration saisonnière des travailleurs est courante parmi les hommes de nombreuses anciennes républiques soviétiques. La recherche ne s'est guère penchée sur les questions de la pratique contraceptive et de l'IVG parmi les femmes de ces contextes à faible fécondité et hauts niveaux de migration, selon le statut de migration du mari.

Méthodes: Les données combinées obtenues de 2280 répondantes à deux enquêtes auprès des femmes mariées de 18 à 45 ans en Arménie rurale-l'une menée en 2005 et l'autre en 2007 -ont servi de base à l'étude. L'association entre le statut de migrant du mari et l'utilisation par son épouse de la pilule ou du stérilet, ou la probabilité qu'elle ait eu une grossesse interrompue volontairement, a été examinée par analyses de régression logistique. D'autres analyses ont été effectuées pour déterminer l'effet éventuellement modérateur de la richesse du ménage.

Résultats: Les épouses des hommes migrants se sont avérées moins susceptibles que celles des non migrants d'utiliser la pilule ou le stérilet $(\mathrm{OR}, 0,6)$. La probabilité de la pratique d'une méthode augmente avec la richesse du ménage parmi les épouses d'hommes non migrants, mais elle diminue légèrement parmi celles d'hommes migrants. Dans l'ensemble, la probabilité qu'une grossesse aboutisse sur un avortement ne diffère pas en fonction du statut de migration. Cependant, la probabilité de l'IVG augmente avec la richesse du ménage parmi les femmes mariées à des hommes non migrants, mais pas parmi celles mariées à des hommes migrants.

Conclusions: Malgrél'absence du mari, lesépouses d'hommes migrants peuvent présenter un taux de grossesse non désirée similaire à celui des épouses d'hommes non migrants. L'amélioration de l'accès aux méthodes contraceptives modernes est vraisemblablement associée positivement à la pratique contraceptive parmi les femmes mariées à des hommes non migrants, mais pas parmi les épouses d'hommes migrants.

Author contact: arusyak.sevoyan@adelaide.edu.au 